\title{
Volatile Organic Compounds in the Ventilation Air before and After the Biofilter of a Mechanical Waste Treatment Plant
}

\author{
Christof Lanzerstorfer ${ }^{1}$, Bernhard Drach ${ }^{1,2}$, Friedrich Pröll ${ }^{2}$ \\ ${ }^{1}$ Process Engineering and Production Institute/University of Applied Sciences Upper Austria \\ Stelzhamerstraße 23, Wels, Austria \\ c.lanzerstorfer@fh-wels.at \\ ${ }^{2}$ FP Ablusttechnik \\ Unterhömbach 14, Neuhofen/Ybbs, Austria \\ f.proell@fp-ablufttechnik.at
}

\begin{abstract}
The ventilation air from mechanical waste treatment plants is contaminated with volatile organic compounds and odour. For the treatment of such air biofilters are usually applied. In this study the separation efficiency of an industrial biofilter was investigated. The separation efficiency of the biofilter for VOCs was significantly lower than the reduction efficiency for odour. This could be attributed mostly to the alkanes, especially the $\mathrm{C} 3-\mathrm{C} 4$ alkanes, contained in the ventilation air. The calculated emission rates for total VOCs and for $\mathrm{C} 3-\mathrm{C} 4$ alkanes were $54 \mathrm{gC}$ per tonne of waste and $17 \mathrm{gC}$ per tonne of waste, respectively.
\end{abstract}

Keywords: Biofilter, volatile organic compounds, mechanical waste treatment

\section{Introduction}

In modern waste management, the aim is not only waste disposal but the recognition of waste as a source of secondary raw materials. Therefore, careful treatment and sorting is the basis for the recycling of materials, for use in waste-to-energy processes or any other utilisation of waste. The ventilation air from plants for the treatment of waste is loaded with some volatile organic compounds (VOC) and odour. Such air has to be treated before it can be released to the atmosphere. For the treatment of ventilation air which is contaminated with VOC and odour biofilters are commonly used [1-3]. In the literature some data on the composition of the VOCs emitted from municipal solid waste at different stages of decomposition are available [4]. For the ventilation air of mechanical treatment of municipal solid waste no data were found.

In this paper the results of a study on the correlation of reduction efficiency of a biofilter for volatile organic compounds (VOC) and odour was investigated. The measurements were performed at a biofilter which is installed at a mechanical waste treatment plant for cleaning the ventilation air.

\section{Material and methods}

The study was performed at a mechanical waste treatment plant. The plant consists of a hall for delivery, bunker storage and crushing of the waste. The waste is crushed by two parallel shredders. Afterwards the crushed waste is transferred into the second hall, where the sorting plant is situated. The ventilation air released from the plant is cleaned in two steps. The cleaning step consists of a scrubber system which removes dust from the air. The second step is a biofilter for reduction of VOC and odour emissions. The biofilter consists of 10 containers, each with the dimensions $12.2 \mathrm{~m} \times 2.4 \mathrm{~m} \times 2.8 \mathrm{~m}$. The biofilter containers are filled with a mixture of wood chips and bark mulch. During full load operation of the plant the amount of ventilation air is 40,000 $\mathrm{m}^{3} / \mathrm{h}$. This operation takes place from 06:00 am. until 06:00 pm. During night operation and at weekends the amount of ventilation air is $10,000 \mathrm{~m}^{3} / \mathrm{h}$. The capacity of the waste treatment plant is approximately $1850 \mathrm{t}$ of waste per week. [5].

For the continuous measurement of the organic hydrocarbon concentration (VOC) concentration two FID instruments (one Ratfisch RS53-T and one Testa FID 2010 T) were used. Both FIDs were calibrated using a certified calibration from Linde (83.5 ppm propane in nitrogen). From the measured results half-hourly average values were computed and recorded in $\mathrm{mg}$ of $\mathrm{C}$ per $\mathrm{m}^{3}$. 
The concentration of odour was measured by olfactometry, according to DIN EN 13725 [6]. For determining odour three rounds with four volunteers were performed. The result is shown in odour units per $\mathrm{m}^{3}\left(\mathrm{OU} / \mathrm{m}^{3}\right)$.

For detailed analysis of the composition of the organic hydrocarbons in an external laboratory, samples of the air were taken in special plastic bags before the scrubber and after the biofilter. The samples were analyzed by gas chromatography mass spectroscopy (GC-MS).

\section{Results}

The typical course of the VOC concentration in the clean gas after the biofilter is shown in Fig. 1. The concentration is given as half-hourly average values. The operation of the waste processing plant during the day shift for five days a week is clearly represented by the concentration curve. During the night and at the weekend the concentrations are substantially lower.

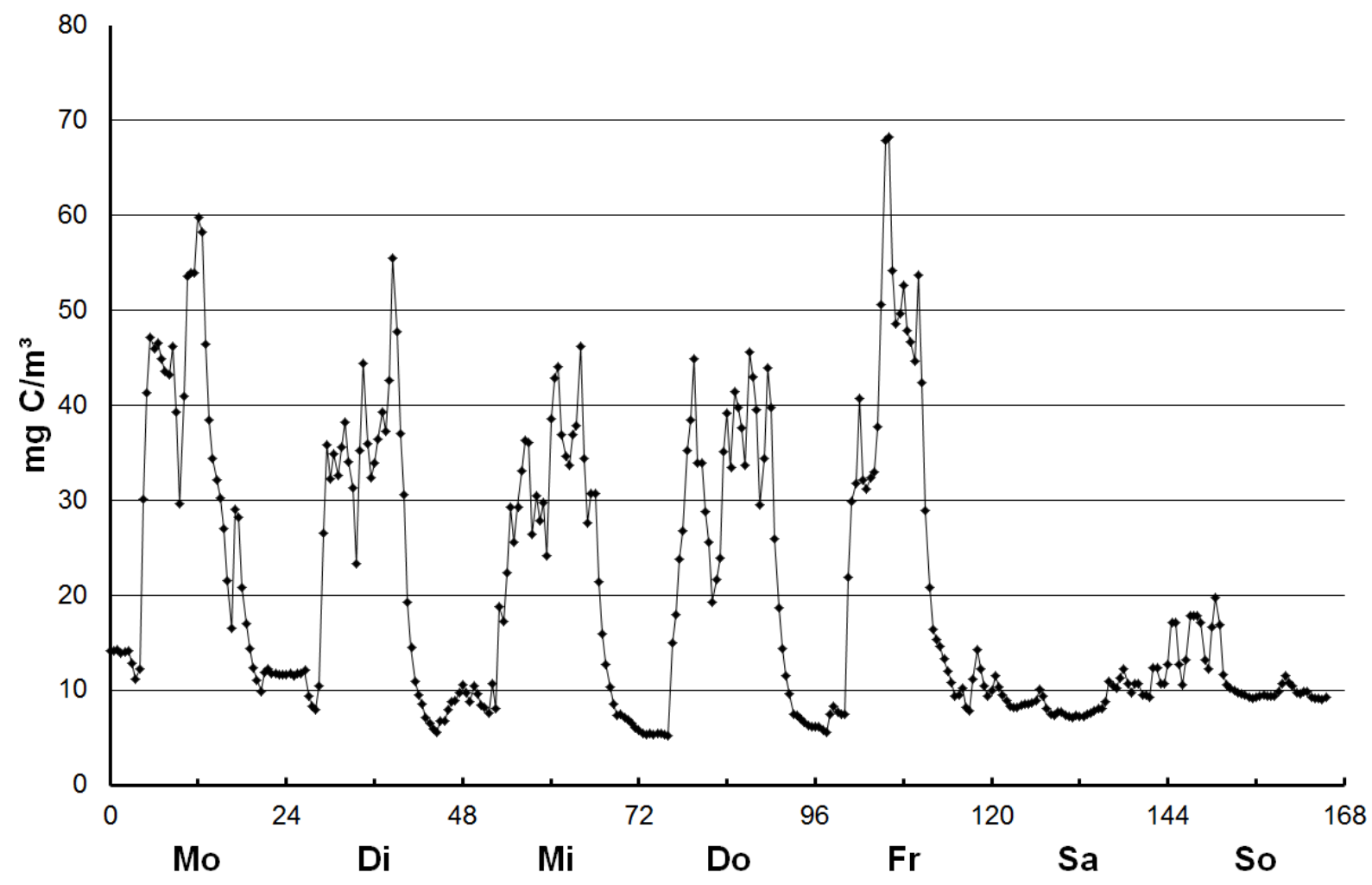

Fig. 1: VOC concentration in the clean gas after the biofilter.

For the plant operation periods the average VOC concentration was $37 \mathrm{mg} \mathrm{C} / \mathrm{m}^{3}$, while for the night and the weekend the average VOC concentration was $10 \mathrm{mg} \mathrm{C} / \mathrm{m}^{3}$. In comparison to the VOC emissions reported from biofilters after composting solid waste the measured VOC concentration was significantly lower [7].

In Fig. 2 the correlation of the reduction of the VOC concentration and the reduction of odour is shown. Generally, the reduction of the VOC concentration is lower. Three data points from another study on biofilters are also included in this presentation [8]. The ventilation air treated with biofilters investigated in this study originated from various other processes (roasting plant in the food industry, waste treatment plant, paint shop for machine parts). The correlation of the reduction of the VOC concentration (in \%) with the reduction of odour (in \%) for both studies can be expressed by Eq 1. The correlation coefficient for the relation was 0.85 . For the results from this study the correlation is quite different (Eq. 2). The correlation coefficient for the relation was nearly 1.0. The extrapolation of the regression line is approximately parallel to the equality line with a vertical distance of roughly $40 \%$ VOC reduction.

$$
\mathrm{VOC}_{\text {red }}=0.48 \mathrm{OU}_{\mathrm{red}}+0.4
$$




$$
V O C_{\text {red }}=0.910 U_{\text {red }}-35
$$

The shift of the line indicates that there are some quite odourless VOCs in the ventilation air which are not separated in the biofilter.

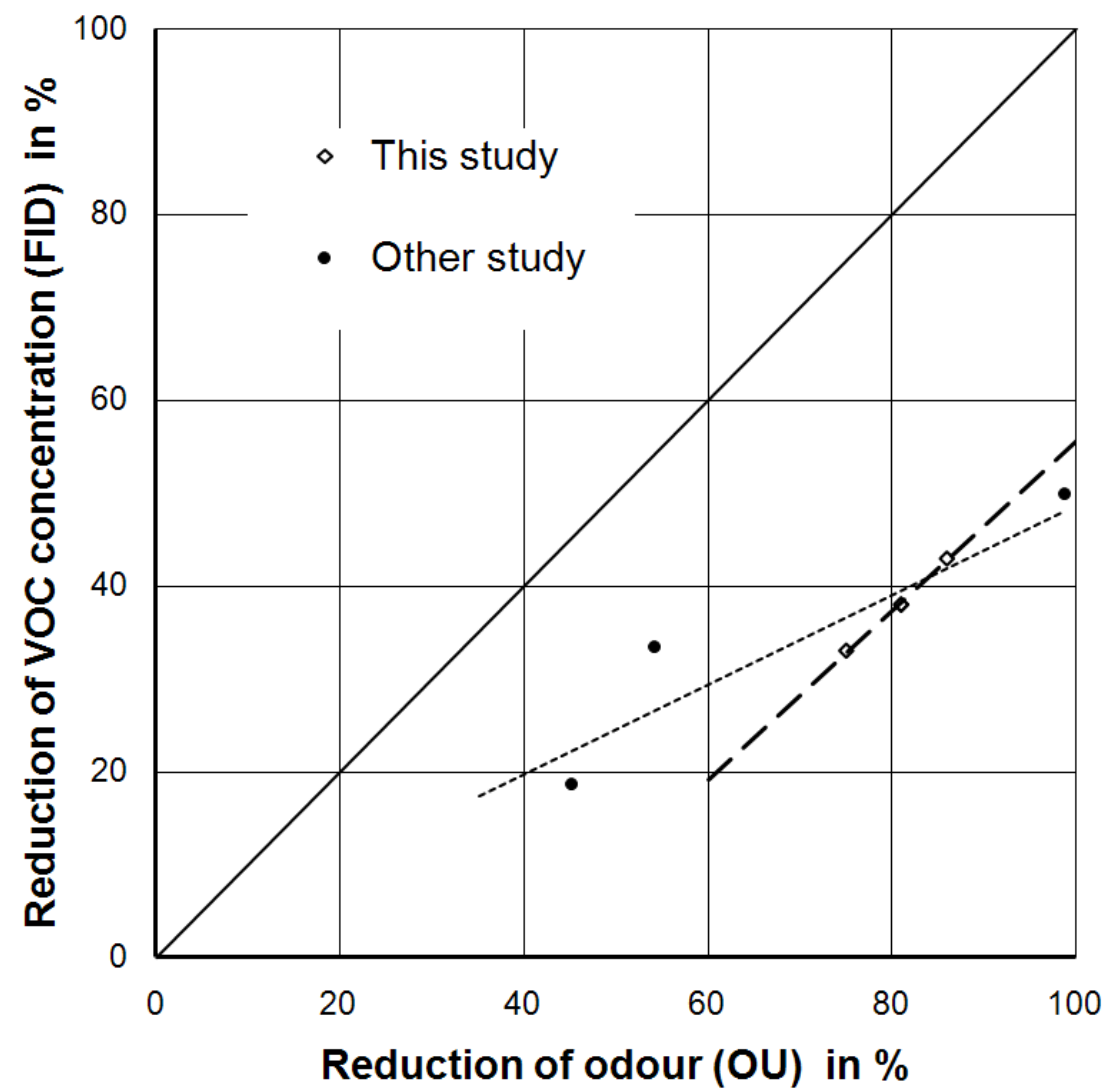

Fig. 2: Correlation of the reduction of the VOC concentration with the reduction of odour.

In Table 1 the results of the GC analysis of the air samples are summarized. During plant operation the light hydrocarbons propane, isobutene and butane accounted roughly for one third of the hydrocarbons after the biofilter. As to be expected, these hydrocarbons pass the gas cleaning system (scrubber system and biofilter) without a reduction in the concentration. For the other organic components (C5-C14) the reduction efficiency depends on the component class they belong to. The high occurrence of low molecular alkanes in the ventilation air is a significant difference to the composition of the VOCs emitted from municipal solid waste at different stage of decomposition [4].

With the given ventilation rates and the measured average emission concentrations the total emission of VOC was approximately $100 \mathrm{~kg}$ per week. Based on the processed waste an emission rate of $54 \mathrm{gC}$ per tonne of waste was calculated. The measured fractions of the C3-C4 alkanes were 0.32 and 0.20 during plant operation and during night and weekend, respectively. Under the assumption of these fractions the amount of $\mathrm{C} 3-\mathrm{C} 4$ alkanes in the waste would be $17 \mathrm{gC}$ per tonne of waste. Sources for these light hydrocarbons could be lighters, propellants of aerosol cans, LPG cans, etc.

For the higher alkanes, which are reduced by the system to a small extent, the emissions are approximately twice as high.

\section{Conclusion}

The occurrence and composition of VOCs in the ventilation air of a mechanical waste treatment plant was investigated. The VOC concentration in the air was lower compared to the concentration reported for the composition of solid waste. Also the composition of the VOCs differed to those emitted from municipal solid waste during decomposition. 
The separation efficiency of the biofilter for VOCs was significantly lower than the reduction efficiency for odour. This was attributed mostly to the alkanes, especially the $\mathrm{C} 3-\mathrm{C} 4$ alkanes, contained in the ventilation air.

The calculated emission rates for VOCs and for C3-C4 alkanes were $54 \mathrm{gC}$ per tonne of treated waste and $17 \mathrm{gC}$ per tonne of treated waste respectively.

Table 1: Concentration of various organic compounds in $\mathrm{mg} / \mathrm{m}^{3}$.

\begin{tabular}{|c|c|c|c|c|}
\hline & \multicolumn{2}{|c|}{ Sample "Plant in Operation" } & \multicolumn{2}{|c|}{ Sample "During Night" } \\
\hline & Before scrubber & After biofilter & Before scrubber & After biofilter \\
\hline Propane & 0.66 & 0.70 & $<$ LOD & $<$ LOD \\
\hline Isobutane & 3.33 & 3.41 & 0.28 & 0.16 \\
\hline Butane & 1.22 & 1.31 & 0.15 & 0.12 \\
\hline SUM C3-C4 alkanes & 5.21 & 5.41 & 0.43 & 0.28 \\
\hline Sum C5 - C14 alkanes & 9.74 & 8.15 & 1.36 & 0.52 \\
\hline Sum of alicyclic hydrocarbons & 0.31 & 0.31 & 0.11 & 0.05 \\
\hline Sum of aromatic hydrocarbons & 3.08 & 2.19 & 0.18 & 0.03 \\
\hline Sum of alcohols & 3.06 & 0.40 & 0.68 & 0.47 \\
\hline Sum of aldehydes and ketones & 0.53 & $<$ LOD & 0.39 & 0.03 \\
\hline Sum of carboxylic acid esters & 3.02 & 0.24 & 0.22 & $<$ LOD \\
\hline Sum of terpenes & 0.76 & 0.33 & 0.07 & $<$ LOD \\
\hline SUM of C5-C14 VOCs & 20.51 & 11.62 & 3.01 & 1.11 \\
\hline SUM of VOCs & 25.72 & 17.03 & 3.44 & 1.39 \\
\hline
\end{tabular}

\section{References}

[1] B. M. Converse, E. D. Schroeder, R. Iranpour, H. H. Cox, and M. A. Deshusses, "Odor and volatile organic compound removal from wastewater treatment plant headworks ventilation using a biofilter," Water Environ. Res., vol. 75, no. 5, pp. 444-454, 2003.

[2] F. I. Khan and A. K. Ghoshal, "Removal of Volatile Organic Compounds from polluted air," J. Loss Prevent. Proc., vol. 13, no. 6, pp. 527-545, 2000.

[3] R. Iranpour, H. H. J. Cox, M. A. Deshusses, and E. D. Schroeder, "Literature Review of Air Pollution Control Biofilters and Biotrickling Filters for Odor and Volatile Organic Compound Removal," Environ. Prog., vol. 24, no. 3, pp. 254267, 2005.

[4] B. Scaglia, V. Orzi, A. Artola, X. Font, E. Davoli, A. Sanchez, and F. Adani, "Odours and volatile organic compounds emitted from municipal solid waste at different stage of decomposition and relationship with biological stability," Bioresource Technol., vol. 102, no. 7, pp. 4638-4645, 2011.

[5] B. Drach, "Process optimizing of the exhaust air treatment system of a waste treatment plant," Master Thesis, School of Engineering and Environmental Sciences, University of Applied Sciences Upper Austria, Wels, Austria, 2016.

[6] DIN EN 13725, "Luftbeschaffenheit - Bestimmung der Geruchsstoffkonzentration mit dynamischer Olfaktometrie (Air quality - Determination of odour concentration by dynamic olfactometry)," Österreichisches Normungsinstitut, Wien, 2003.

[7] E. Pagans, X. Font, and A. Sánchez, "Emission of volatile organic compounds from composting of different solid wastes: Abatement by biofiltration," J. Hazard. Mater., vol. B131, no. 1-3, pp. 179-186, 2006.

[8] B. Drach, "Erprobung einer neuen Messmethode zur Überwachung von Biofiltern," Bachelor Thesis, School of Engineering and Environmental Sciences, University of Applied Sciences Upper Austria, Wels, Austria, 2013. 